\title{
One-Dimensional Heat Transfer Analysis for thin Films with Applications in Inertial Fusion Energy
}

S. G. Durbin, R. W. Moir

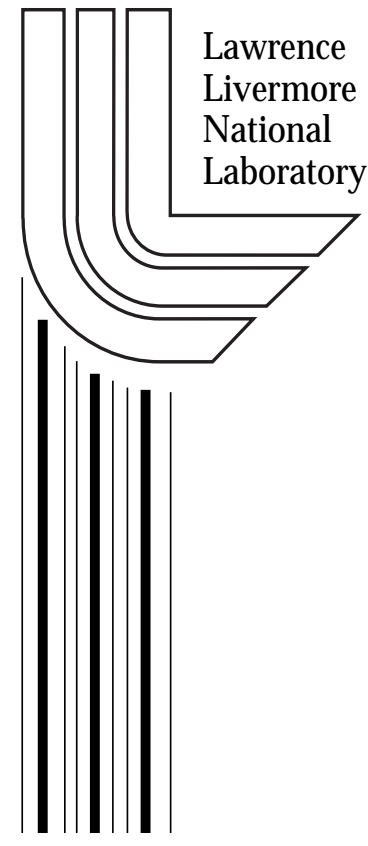

September 21, 2001 


\section{DISCLAIMER}

This document was prepared as an account of work sponsored by an agency of the United States Government. Neither the United States Government nor the University of California nor any of their employees, makes any warranty, express or implied, or assumes any legal liability or responsibility for the accuracy, completeness, or usefulness of any information, apparatus, product, or process disclosed, or represents that its use would not infringe privately owned rights. Reference herein to any specific commercial product, process, or service by trade name, trademark, manufacturer, or otherwise, does not necessarily constitute or imply its endorsement, recommendation, or favoring by the United States Government or the University of California. The views and opinions of authors expressed herein do not necessarily state or reflect those of the United States Government or the University of California, and shall not be used for advertising or product endorsement purposes.

This work was performed under the auspices of the U. S. Department of Energy by the University of California, Lawrence Livermore National Laboratory under Contract No. W-7405-Eng-48.

This report has been reproduced

directly from the best available copy.

Available to DOE and DOE contractors from the

Office of Scientific and Technical Information

P.O. Box 62, Oak Ridge, TN 37831

Prices available from (423) 576-8401

http:/ /apollo.osti.gov/bridge/

Available to the public from the National Technical Information Service

U.S. Department of Commerce 5285 Port Royal Rd., Springfield, VA 22161

http:/ / www.ntis.gov/

OR

Lawrence Livermore National Laboratory

Technical Information Department's Digital Library

http://www.llnl.gov/tid/Library.html 


\title{
One-dimensional heat transfer analysis for thin films with applications in inertial fusion energy
}

\author{
S. G. Durbin ${ }^{1}$, R. W. Moir \\ October 16, 2001
}

\begin{abstract}
The x-rays from inertial fusion energy micro explosions deposited in a thin film will lead to a temperature rise dependent on penetration depth and time duration. This temperature rise is important to the study of surface tension driven flows and the surface quality of films for optics. A one-dimensional heat transfer analysis is used to estimate the film temperature rise for several different cases applicable to both final optical surfaces and renewable liquid first walls. Attenuating gas mixtures of xenon and krypton are considered to mitigate the deposition of x-ray energy.
\end{abstract}

\section{Modeling}

The system is modeled as one-dimensional, transient heat transfer into a plane wall with prescribed boundary conditions and volumetric heat generation. The timescale of the photon energy deposition is much smaller than the convective timescale of the flow. As a result, the coolant is considered to be stationary during the heat transfer process. The curvature of the chamber is also neglected for the first wall case in order to simplify analysis. Film properties are dependent on temperature.

\section{Thermal Modeling}

The thermal diffusion equation for a plane wall analysis of a thin film is

$\rho \cdot \mathrm{c}_{\mathrm{p}} \frac{\partial \mathrm{T}}{\partial \mathrm{t}}=\frac{\partial}{\partial \mathrm{x}}\left(\mathrm{k} \frac{\partial \mathrm{T}}{\partial \mathrm{x}}\right)+\mathrm{q}^{\prime \prime \prime}(\mathrm{x})$

where $\mathrm{T} \equiv$ temperature $[\mathrm{K}]$

$\mathrm{k}(\mathrm{T}) \equiv$ temperature dependent thermal conductivity $[\mathrm{W} / \mathrm{m} \cdot \mathrm{K}]$

$\rho(\mathrm{T}) \equiv$ temperature dependent density $\left[\mathrm{g} / \mathrm{cm}^{3}\right]$

$\mathrm{c}_{\mathrm{p}}(\mathrm{T}) \equiv$ temperature dependent specific heat $[\mathrm{J} / \mathrm{g} \cdot \mathrm{K}]$

$\mathrm{q}^{\prime \prime}$ ' $(\mathrm{x}) \equiv$ spatially dependent volumetric heat generation ${ }^{*}\left[\mathrm{~W} / \mathrm{cm}^{3}\right]$

* Due to photon deposition

\footnotetext{
${ }^{1}$ Georgia Institute of Technology

Address: Mechanical Engineering

731 Ferst St.

Atlanta, GA 30332

Phone: (404) 385-1891
} 
For the case of thermal properties dependent on temperature only, the one-dimensional thermal diffusion equation reduces to the following

$$
\rho \cdot \mathrm{c}_{\mathrm{p}} \frac{\partial \mathrm{T}}{\partial \mathrm{t}}=\frac{\mathrm{dk}}{\mathrm{dT}}\left(\frac{\partial \mathrm{T}}{\partial \mathrm{x}}\right)^{2}+\mathrm{k} \frac{\partial^{2} \mathrm{~T}}{\partial \mathrm{x}^{2}}+\mathrm{q}^{\prime \prime \prime}(\mathrm{x})
$$

Equation 2 is solved for the temperature throughout the film with an explicit numerical method in the heat transfer code (1). Figure 1 gives a schematic of the problem and is applicable to the first wall of a chamber or an optical surface. Both boundary conditions were taken to be adiabatic. This is a valid assumption during the $\mathrm{X}$-ray burst, $\tau=10 \cdot 10^{-9}$ seconds.

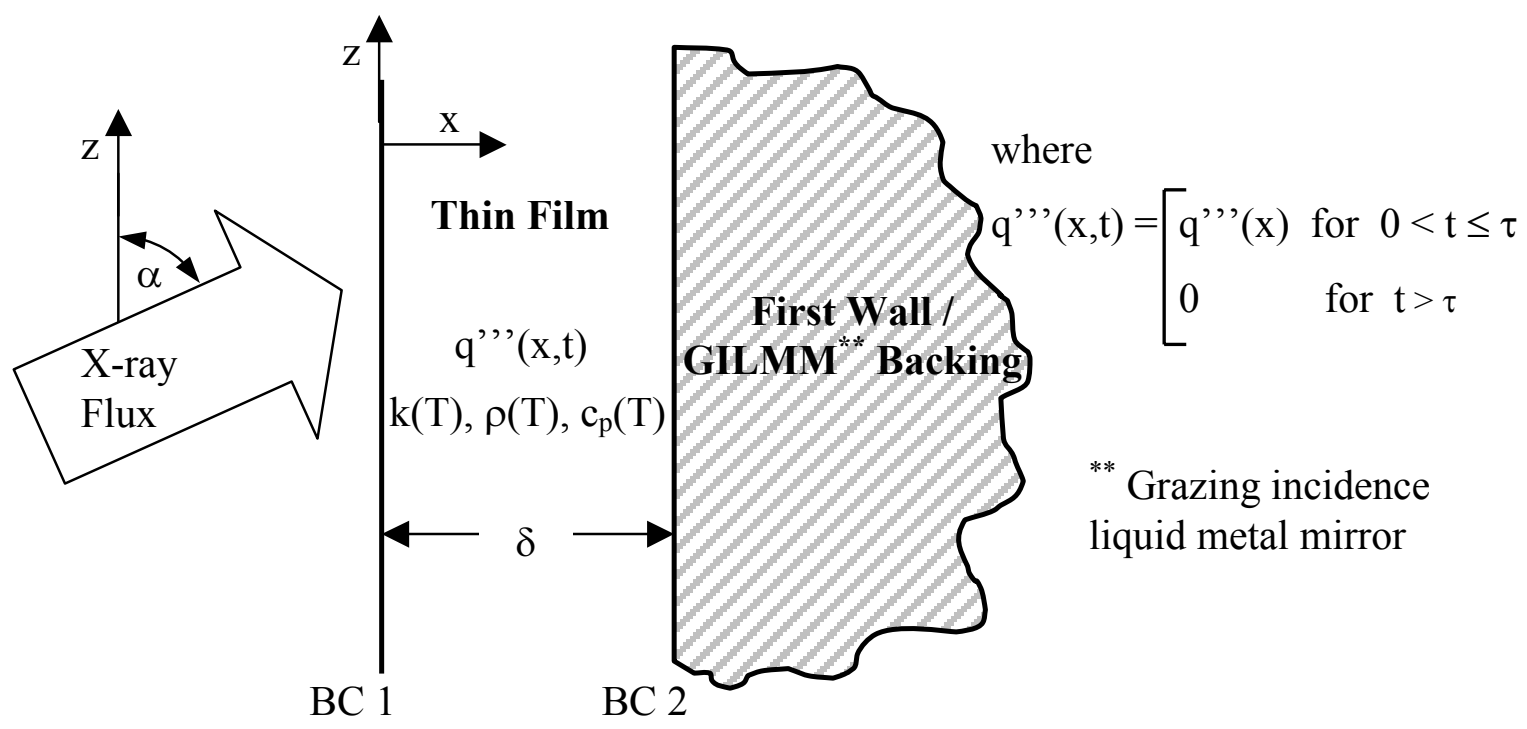

Figure 1: Plane wall analysis of thin film

Given material properties and film geometry, only the volumetric heat generation term is needed to solve for the temperature of the film. The spatially dependent heat generation due to x-ray deposition is calculated with an energy deposition code (2). This energy deposition code takes into account material properties, film thickness/orientation, and characteristics of the incident x-ray flux (e.g spectrum, total energy, etc).

\section{Target Output Spectra Modeling}

The x-ray output energy from the target burn is given by an output spectrum (3). The target spectra used in this report are given in Figure 2. These spectra are for two different targets: 1) the heavy ion indirect-drive target, which might be similar to a laser indirectdrive target and 2) the Naval Research Laboratory direct-drive target. The photons are assumed to arrive in a span of $\tau=10 \cdot 10^{-9}$ seconds. During this span, the output spectrum is assumed constant. This assumption results in a spatially dependent volumetric heat 
generation that is constant with time. For a given spectrum and radius, the volumetric heat generation is then dependent on material and orientation angle $(\alpha)$.

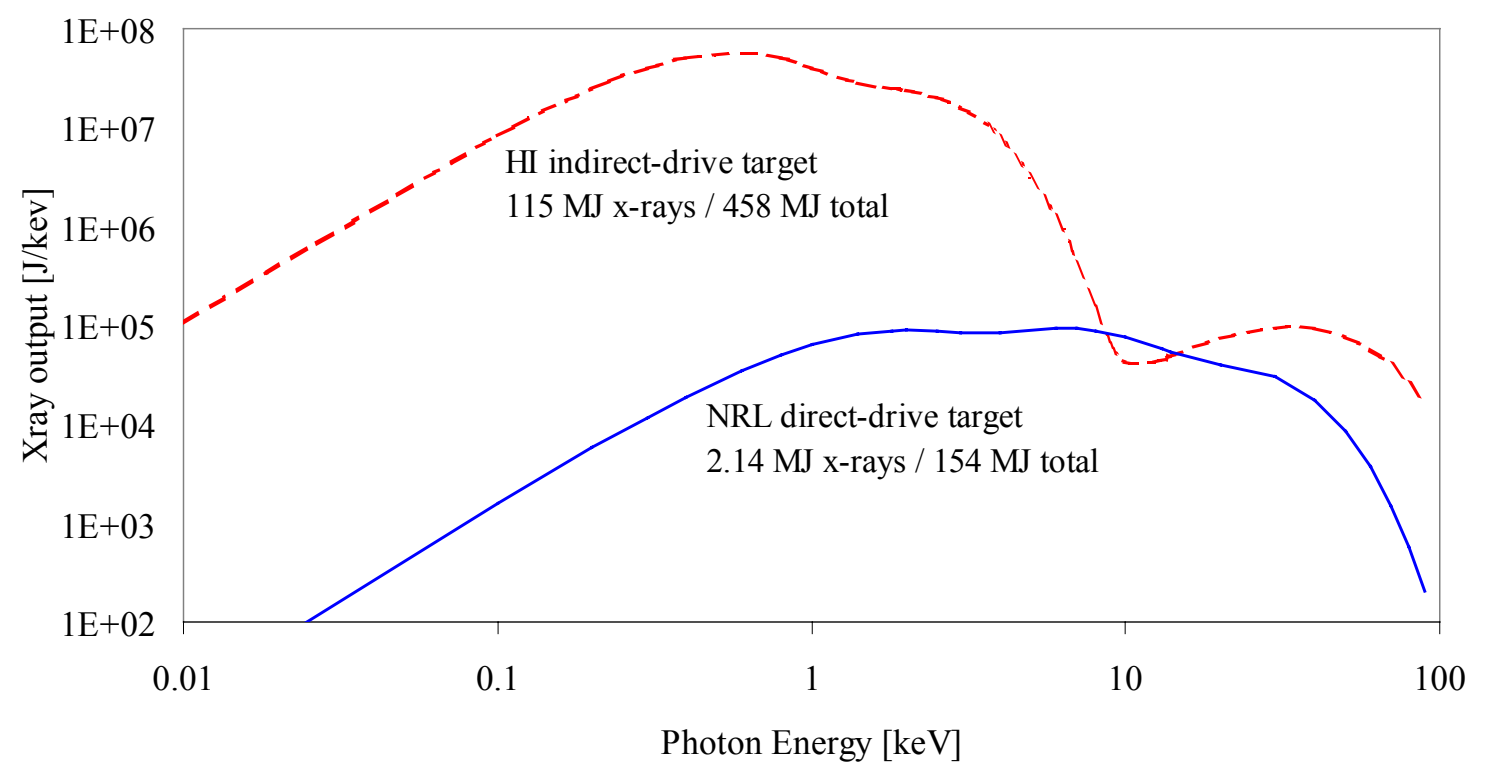

Figure 2: X-ray output spectra

The three temperature blackbody fits for these spectra are given below by equation 3 . Coefficients for each target are shown in Table 1.

$\mathrm{E}(\mathrm{T})=\frac{\mathrm{c}_{1} \mathrm{~T}^{3}}{\exp \left(\mathrm{T} / \mathrm{T}_{1}\right)-1}+\frac{\mathrm{c}_{2} \mathrm{~T}^{3}}{\exp \left(\mathrm{T} / \mathrm{T}_{2}\right)-1}+\frac{\mathrm{c}_{3} \mathrm{~T}^{3}}{\exp \left(\mathrm{T} / \mathrm{T}_{3}\right)-1}[\mathrm{~J} / \mathrm{keV}]$

where $\mathrm{T}$ is photon energy in $[\mathrm{keV}]$

Table 1: Target blackbody coefficients

\begin{tabular}{|l|l|l|l|l|l|l|}
\hline & $\mathrm{c}_{1}$ & $\mathrm{~T}_{1}$ & $\mathrm{c}_{2}$ & $\mathrm{~T}_{2}$ & $\mathrm{c}_{3}$ & $\mathrm{~T}_{3}$ \\
\hline NRL direct-drive & $3.01 \cdot 10^{5}$ & 0.53 & $6.02 \cdot 10^{3}$ & 2.11 & 67.3 & 7.26 \\
\hline HI indirect-drive & $5.73 \cdot 10^{9}$ & 0.183 & $5.84 \cdot 10^{7}$ & 0.65 & 38.9 & 12.0 \\
\hline
\end{tabular}




\section{Energy Deposition Modeling}

The deposition model in this report is based on film material mean free paths. The following definitions are used in this section.

$\mathrm{R} \equiv$ distance from film to fusion event $[\mathrm{m}]$

$\mathrm{E}_{\mathrm{dep}} \equiv$ energy deposition correction factor ${ }^{* * *}$

$\lambda \equiv$ photon mean free path in film $[\mathrm{cm}]$

*** When a photon interacts with an atom via the photoelectric effect, the photon is absorbed, and one of the atomic electrons is ejected from the atom $\left(E_{\text {dep }}=1\right)$. When a photon interacts with an electron, however, it is scattered elastically, and the photon imparts a portion of its energy to the electron $\left(E_{d e p}<1\right)$. While these scattered photons are modeled in radiation transport calculations, such as those using the Monte Carlo method (e.g. TART (4)), they are neglected here.

The equation for energy density as a function of penetration depth is given below.

$$
\Phi(x)=\int_{0.01}^{00} \frac{\mathrm{E}(\mathrm{T})}{4 \pi \cdot \mathrm{R}^{2}} \cdot \mathrm{E}_{\mathrm{dep}}(\mathrm{T}) \frac{\exp (-x / \sin (\alpha) \cdot \lambda(T))}{0.01 \cdot \lambda(\mathrm{T})} \mathrm{dT}\left[\mathrm{J} / \mathrm{m}^{3}\right]
$$

Figures 3 and 4 show the properties for the materials used in this report (4).

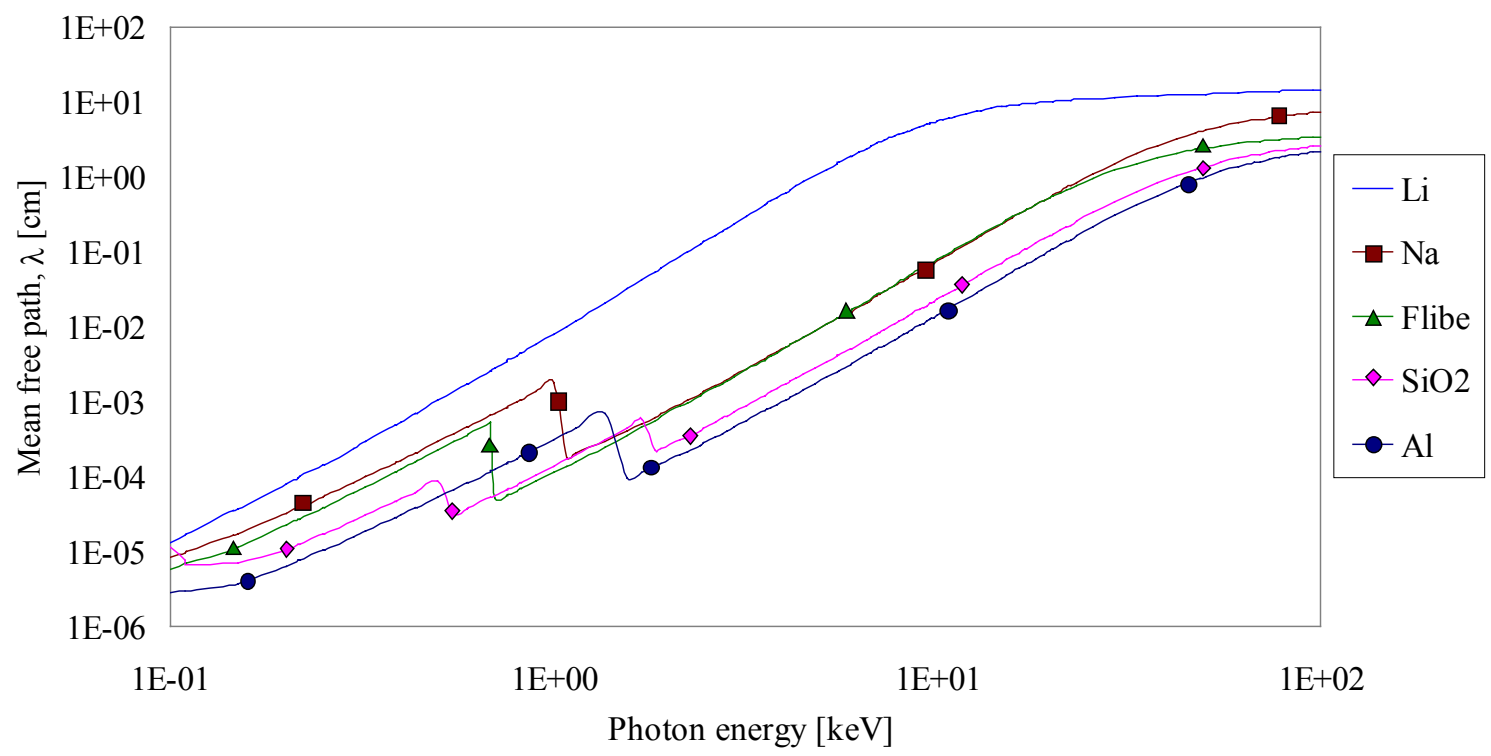

Figure 3: Mean free path vs. photon energy for selected materials 


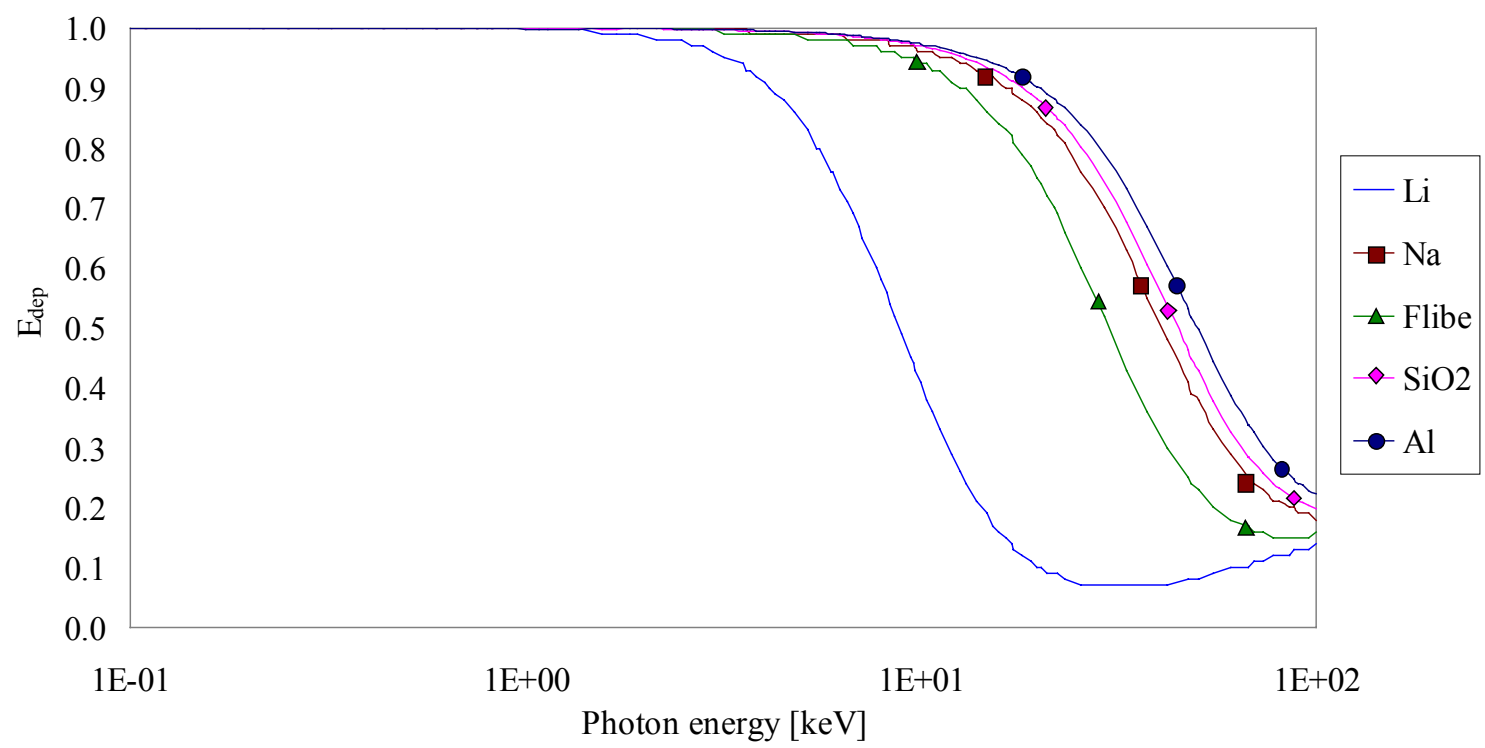

Figure 4: $E_{\text {dep }}$ correction factor vs. photon energy for selected materials

\section{Code Verification}

The energy deposition code was checked against results from the University of California, San Diego (5). The two results are shown below in Figure 5 for a lithium film exposed to the HI indirect-drive target at a distance of $6.5 \mathrm{~m}$. The two results are in excellent agreement.

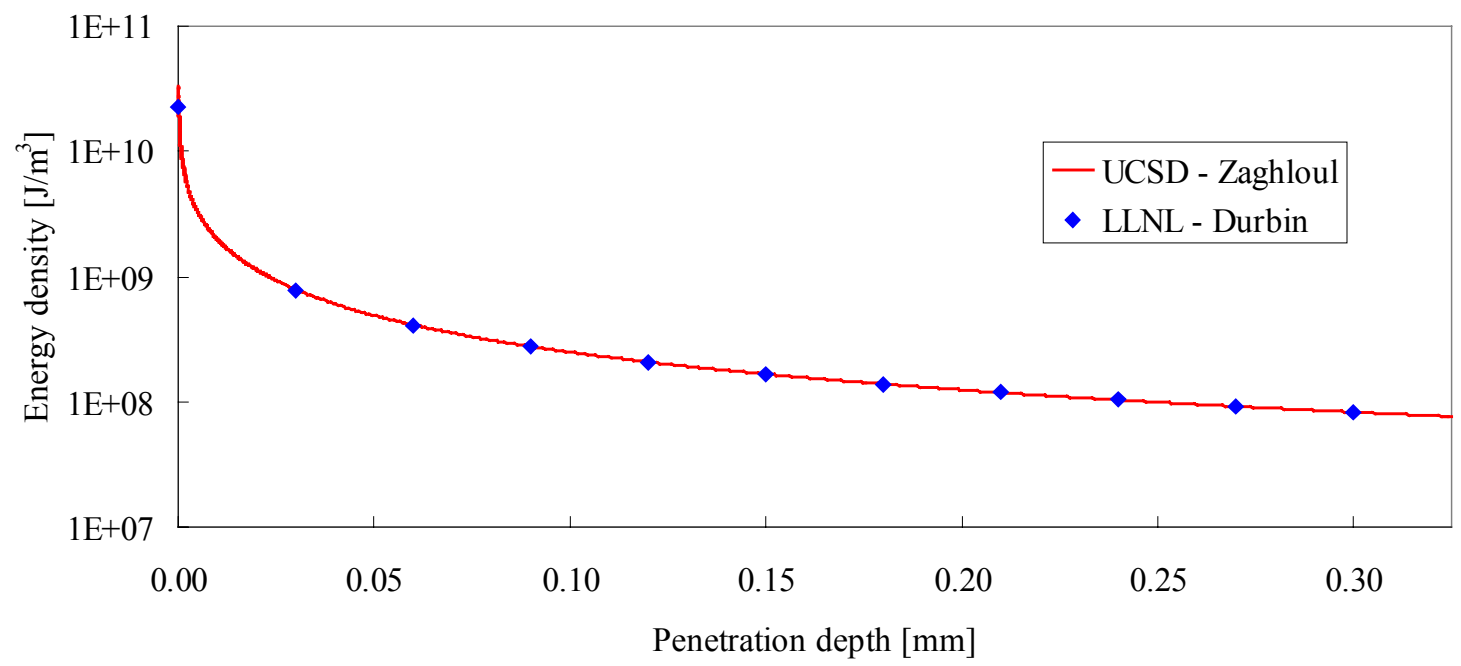

Figure 5: Energy density in a lithium film at $6.5 \mathrm{~m}$ exposed to the $\mathrm{HI}$ indirect-drive target 
The one-dimensional heat transfer code was verified for the case of constant heat flux and constant material properties. The surface temperature results for a sodium film are shown in Figure 6. Again, the results are in excellent agreement.

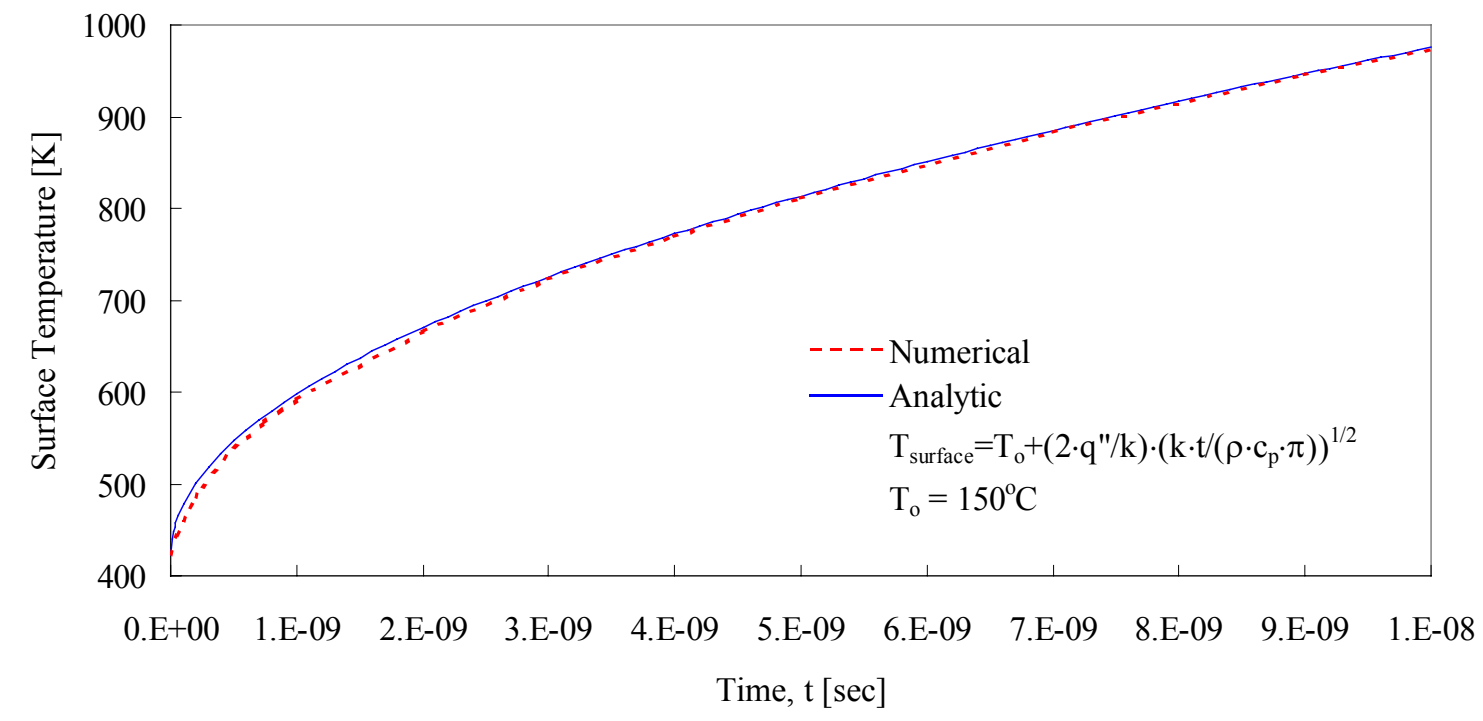

Figure 6: Surface temperature as a function of time for a sodium film exposed to a constant heat flux $\left(\mathrm{q}^{\prime \prime}=5 . \mathrm{E}+6 \mathrm{~W} / \mathrm{cm}^{2}\right)$

\section{Results}

The results contained in this report can be grouped into three categories: unprotected thin films, attenuating gas mixtures, and protected thin films.

Unprotected films consider chambers with thin films on the first wall and GILMM's without intervening gas protection. A general analysis was performed the effects of attenuating gas mixtures of krypton and xenon on energy deposition in thin films. Protected thin films refer to GILMM's with a protective gas layer.

A method for estimating the surface temperature rise of sodium GILMM's at any distance and protective gas line density is also presented. This method couples results from the heat transfer and energy deposition codes.

\section{$\underline{\text { Unprotected Thin Films }}$}

The unprotected thin films refer to those without the benefit of an attenuating gas. These include sacrificial first wall layers and unprotected GILMM's. The NRL direct drive target and the HI indirect-drive targets were both examined. First wall films were exposed to the NRL target, and the GILMM films were exposed to the heavy ion indirectdrive target. The x-ray output of the HI indirect-drive at a typical first wall scenario 
quickly leads to temperatures above the film boiling point. Since the heat transfer code does not accurately model behavior past the boiling point, this case was not studied. The $\mathrm{X}$-ray output of the NRL direct-drive target at optical distances did not lead to significant temperature rises. This case was also not studied.

\section{Chamber First Walls}

First walls were studied to determine the surface temperature variation due to x-ray heating along the chamber wall. This result might be of interest in the study of temperature driven surface tension gradient flows. Figure 7 shows the geometry investigated. The waist offset is defined as the vertical distance measured between the chamber waist radius and the point of interest.

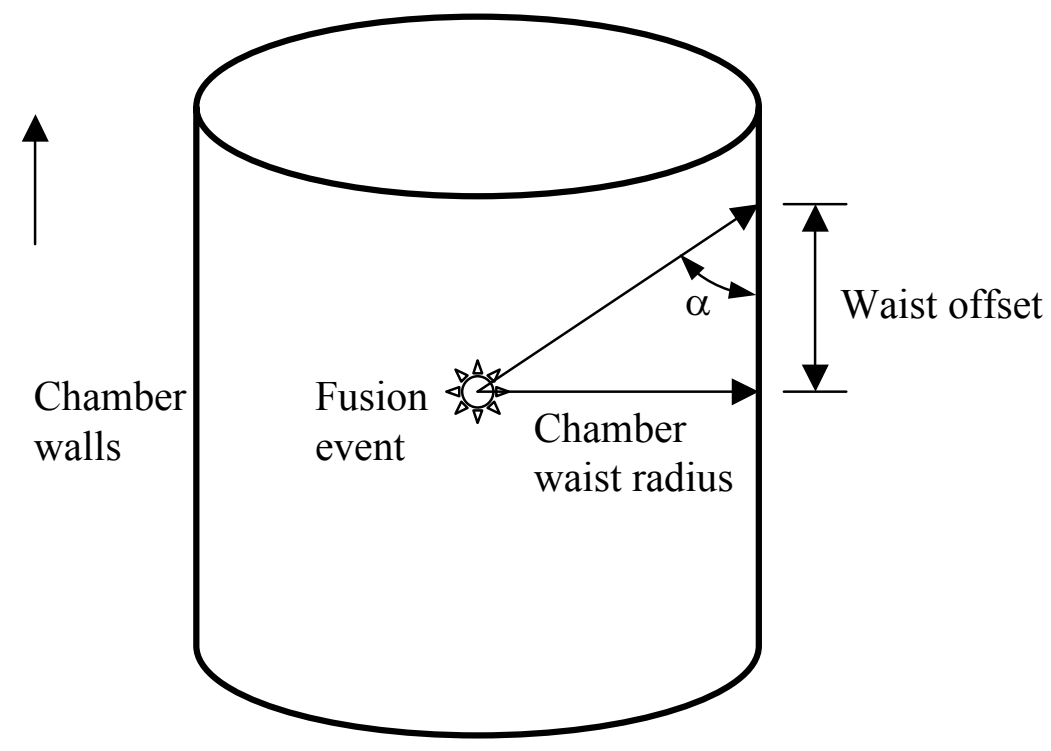

Figure 7: Generic chamber geometry for first wall analysis

The following terminology is defined for clarity.

$\mathrm{T}_{\mathrm{o}} \equiv$ initial temperature

$\Delta \mathrm{T} \equiv$ film surface temperature rise

where mathematically $\Delta \mathrm{T}=\left(\mathrm{T}(\tau)-\mathrm{T}_{\mathrm{o}}\right)_{\text {surface }}$ 
The results for flibe in a chamber with a chamber waist radius of $6 \mathrm{~m}$ are shown below. The chamber walls were exposed to the NRL target. Maximum surface temperature rise is at the chamber waist. The initial temperature of the flibe is $500^{\circ} \mathrm{C}$. A cubic fit to the data is also given.

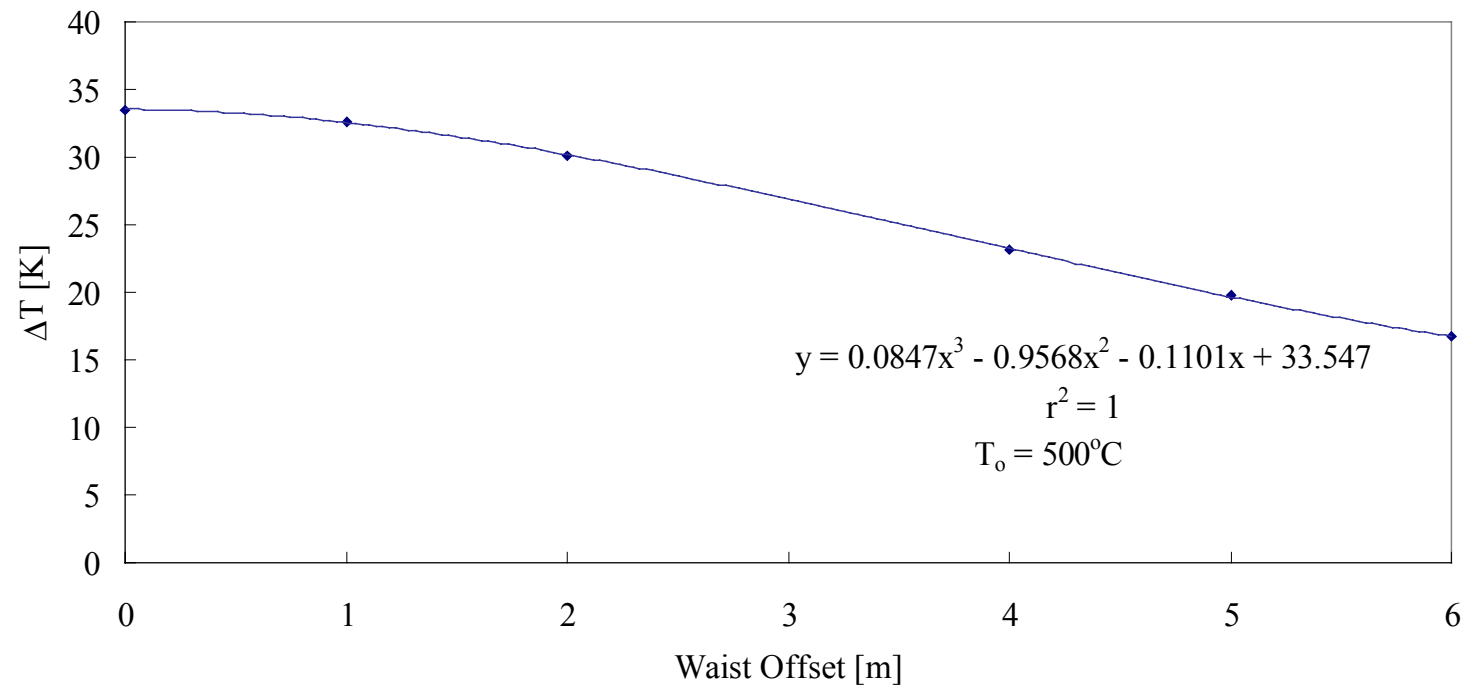

Figure 8: Flibe exposed to NRL direct-drive target

Chamber waist radius $=6 \mathrm{~m}$

\section{Unprotected GILMM's}

Temperature rises for lithium and sodium GILMM's are presented below. The maximum surface temperature rise is shown as a function of orientation angle. Results are for exposure to the HI indirect-drive target at different distances. The highest surface temperature is always at $\alpha=90^{\circ}$. (A typical GILMM angle might be $\alpha=10^{\circ}$.)

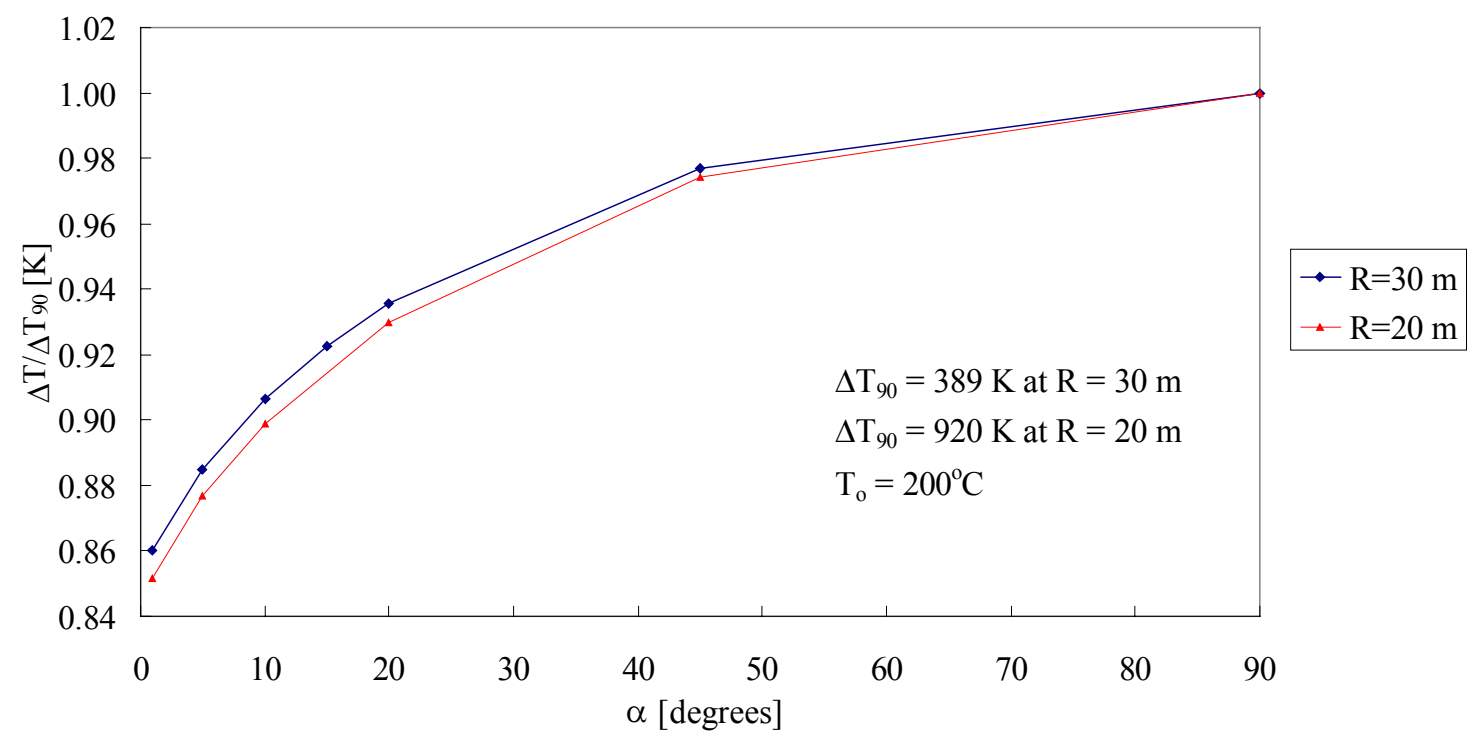

Figure 9: Normalized surface temperature rise as a function of GILMM angle for lithium exposed to $\mathrm{HI}$ indirect-drive target 


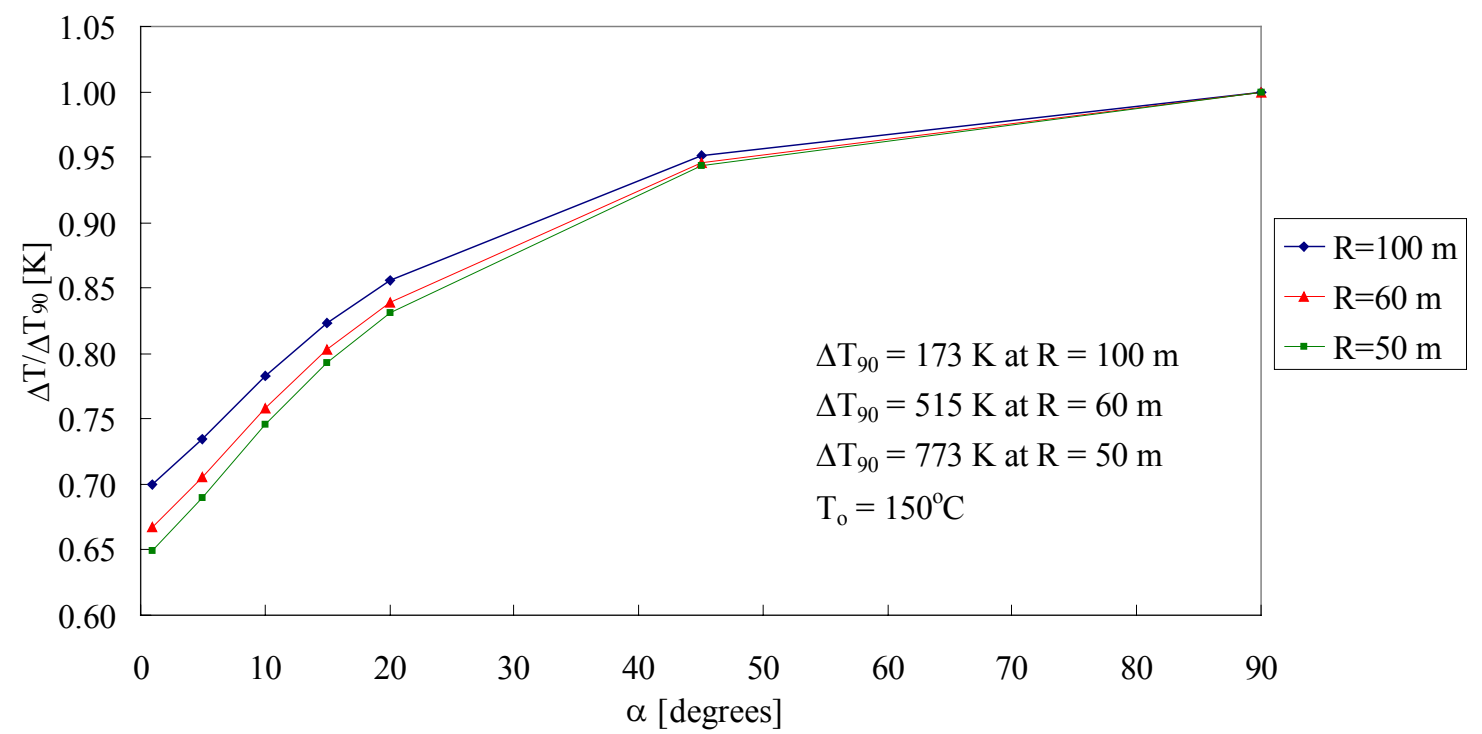

Figure 10: Normalized surface temperature rise as a function of GILMM angle for sodium exposed to $\mathrm{HI}$ indirect-drive target

\section{$\underline{\text { Attenuating Gas Mixtures }}$}

The attenuating effectiveness of krypton-xenon gas mixtures was studied for the heavy ion indirect-drive target. Higher line densities result in lower surface energy densities, which in turn correspond to smaller surface temperature rises. The optimum mixture is dependent on the line density and film material.

The following definitions are used in this section.

$\mathrm{nL} \equiv$ line density $\left[\mathrm{cm}^{-2}\right]$ (gas number density times protective length)

$\Gamma \equiv$ Xe mixture fraction

$\sigma \equiv$ gas cross section $\left[\mathrm{cm}^{2}\right]$

$\sigma_{\text {eff }}=\Gamma \cdot \sigma_{\mathrm{Xe}}+(1-\Gamma) \cdot \sigma_{\mathrm{Kr}}\left[\mathrm{cm}^{2}\right]$

The spectrum after it has passed through the attenuating gas, $\mathrm{E}_{\text {atten }}$, is

$\left.\mathrm{E}_{\text {atten }}(\mathrm{T})=\mathrm{E}(\mathrm{T}) \cdot \exp \left(-\mathrm{nL} \cdot \sigma_{\text {eff }}\right) \quad \mid \mathrm{J} / \mathrm{keV}\right\rfloor$

\section{Surface X-ray Flux}

The surface x-ray flux at a given radius is

$\varphi(\Gamma)=\int_{0.01}^{00} \frac{\mathrm{E}_{\text {atten }}(\Gamma, \mathrm{T})}{4 \pi \cdot \mathrm{R}^{2}} \mathrm{dT} \quad\left[\mathrm{J} / \mathrm{m}^{2}\right]$ 
Figure 11 below gives the surface flux for different line densities and gas compositions.

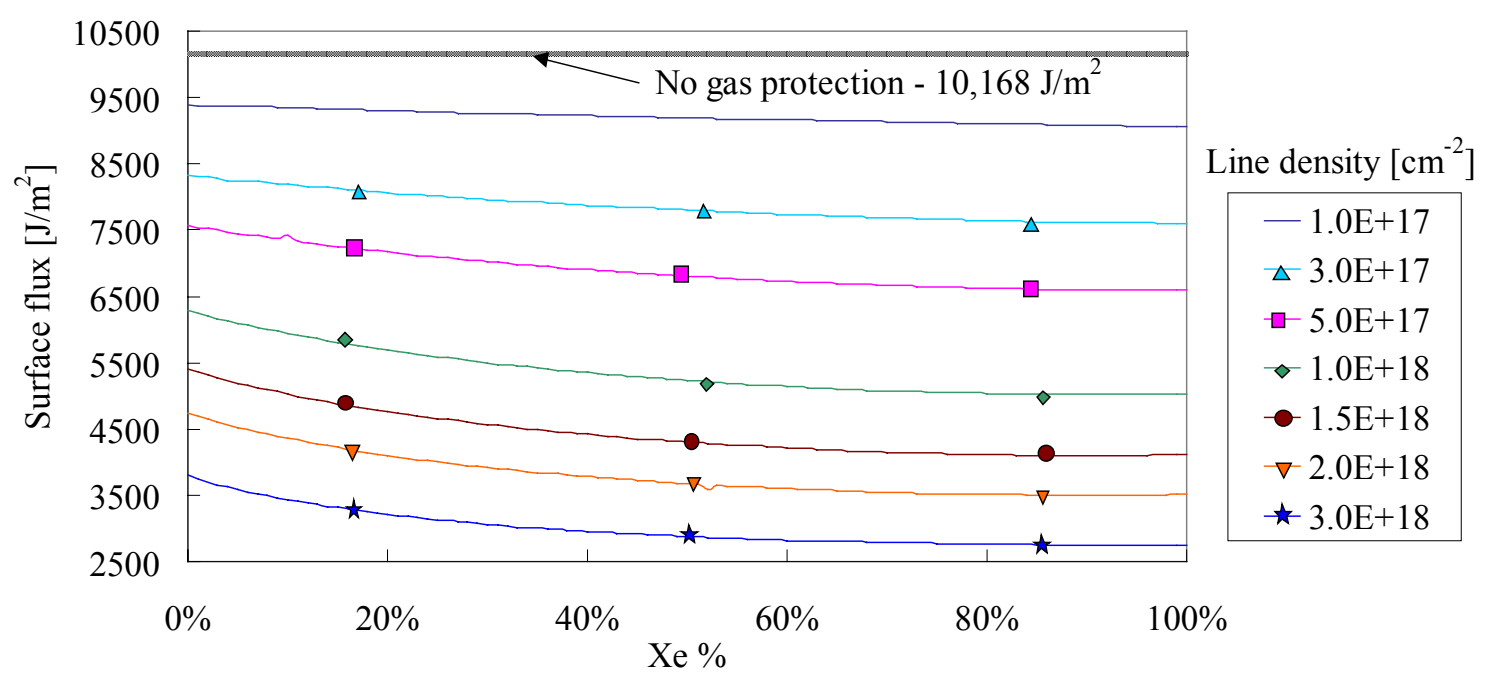

Figure 11: Surface energy flux from $\mathrm{HI}$ indirect target at $30 \mathrm{~m}$ vs. attenuating gas composition $(\mathrm{Xe}, \mathrm{Kr})$

\section{Surface Energy Density}

The surface energy density, $\Phi(\mathrm{x}=0)$, is given by

$\left.\Phi(\Gamma)\right|_{\mathrm{x}=0}=\int_{0.01}^{100} \frac{\mathrm{E}_{\text {atten }}(\Gamma, \mathrm{T})}{4 \pi \cdot \mathrm{R}^{2}} \cdot \frac{\mathrm{E}_{\mathrm{dep}}(\mathrm{T})}{0.01 \cdot \lambda(\mathrm{T})} \mathrm{dT} \quad\left[\mathrm{J} / \mathrm{m}^{3}\right]$

The results for the materials under consideration in this study are summarized in the figures to follow. The materials considered are sodium, lithium, aluminum, and silicon dioxide (silica). All plots give the resultant surface energy densities from protected scenarios as well as the value of the unprotected case. Sodium was studied extensively as a leading GILMM candidate. 
The plot for sodium indicates the surface energy density regime that leads to surface temperatures above the boiling point at STP. This limit is set conservatively for an orientation angle of $\alpha=90^{\circ}$ (the $10^{\circ}$ limit is also shown). Note: Surface energy density is independent of orientation angle.

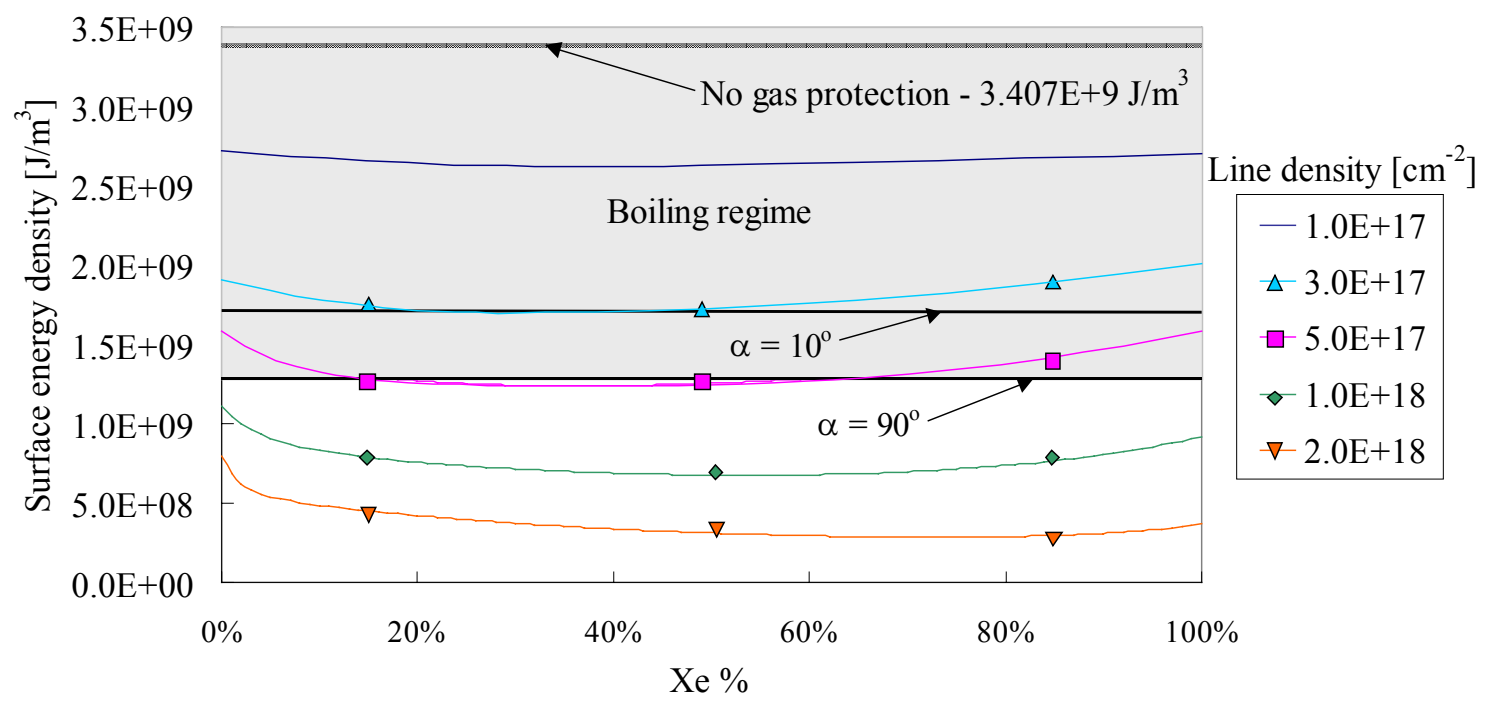

Figure 12: Surface energy density for sodium at $30 \mathrm{~m}$ vs. attenuating gas composition $(\mathrm{Xe}, \mathrm{Kr})$

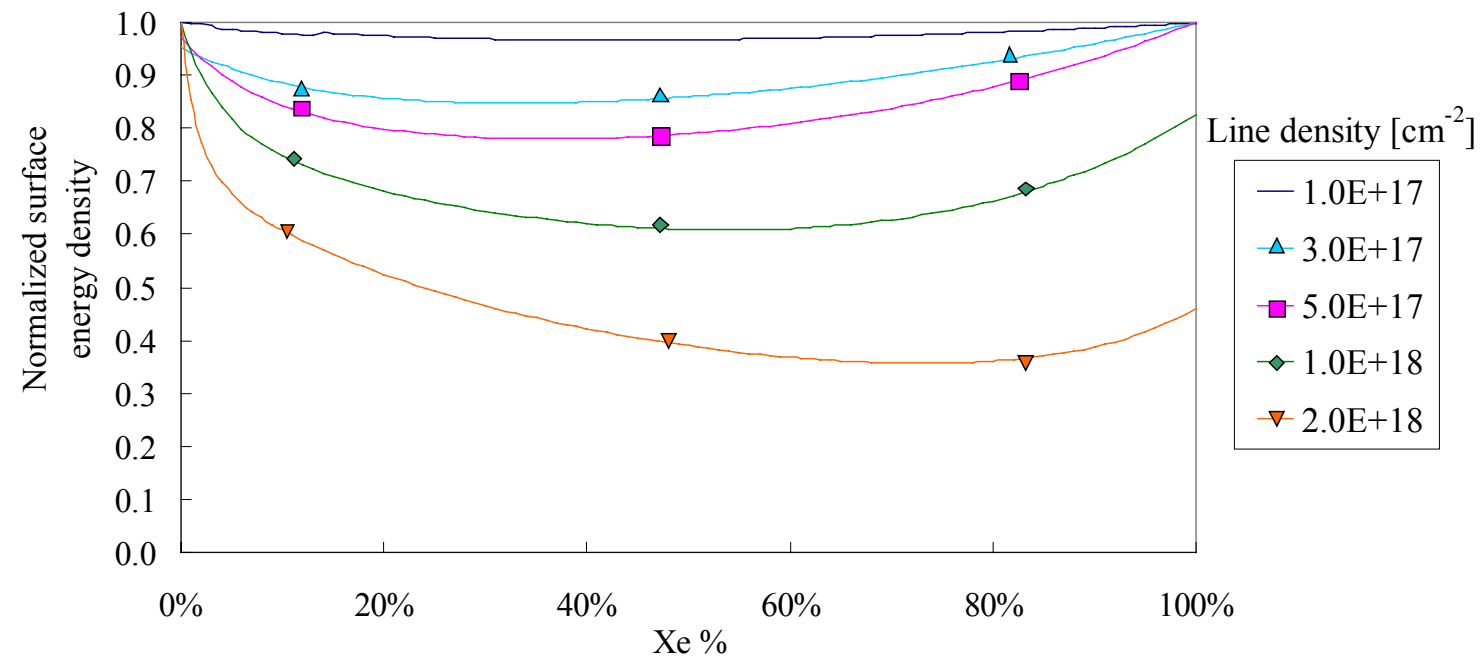

Figure 13: Normalized surface energy density for sodium at $30 \mathrm{~m}$ vs. attenuating gas composition (Xe, $\mathrm{Kr}$ ) 
Next are the results for lithium. The gas mixtures have a greater attenuating effect, which is easily seen by comparing the normalized surface energy density graph with that of sodium.

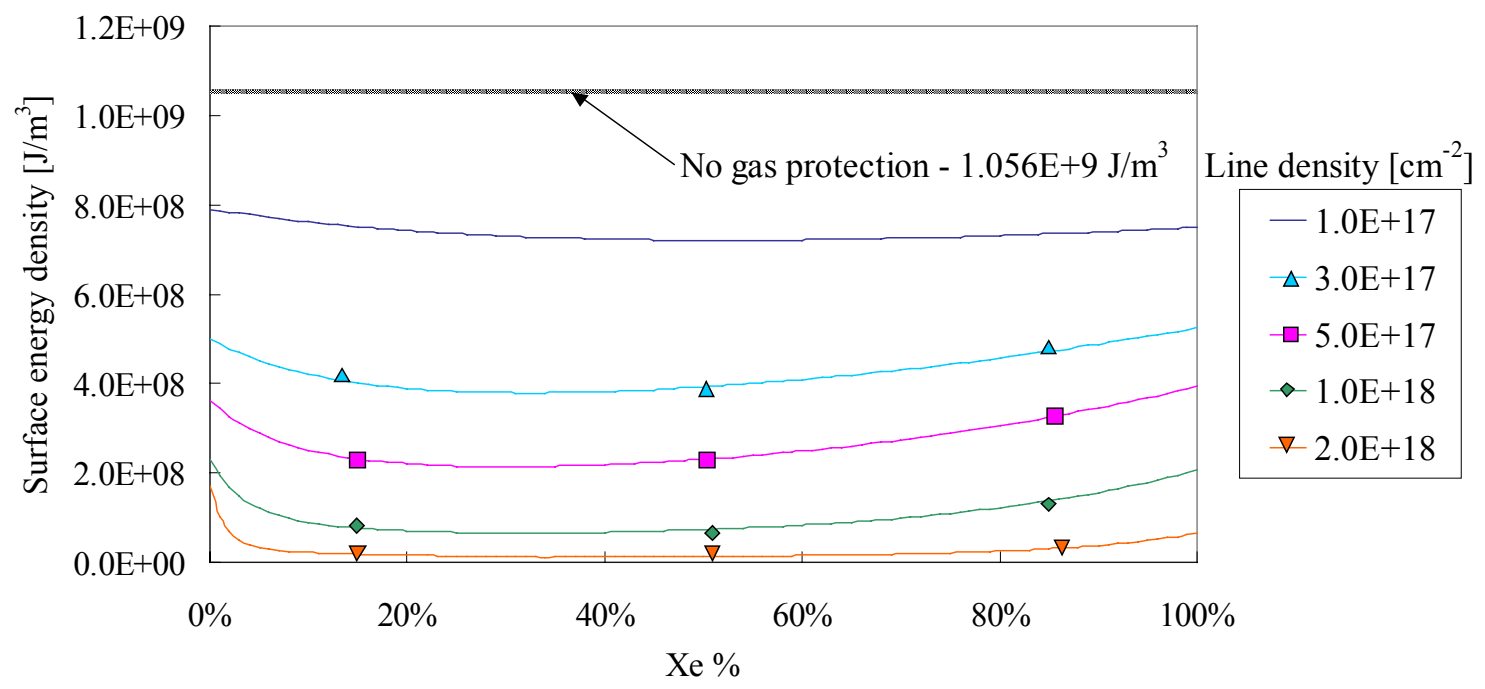

Figure 14: Surface energy density for lithium at $30 \mathrm{~m}$ vs. attenuating gas composition ( $\mathrm{Xe}, \mathrm{Kr})$

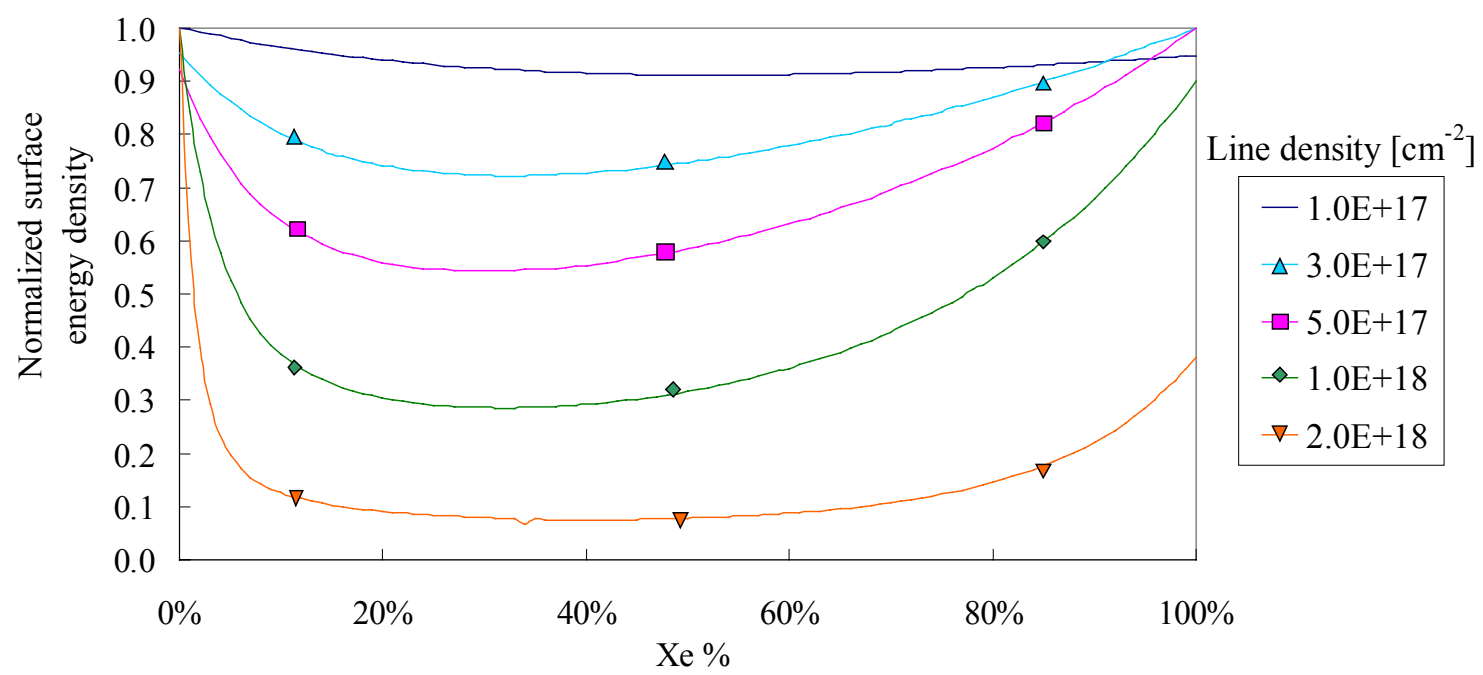

Figure 15: Normalized surface energy density for lithium at $30 \mathrm{~m}$ vs. attenuating gas composition (Xe, $\mathrm{Kr})$ 
The case of an aluminum optic is shown below. Higher line densities than those needed by lithium and sodium are required to have a significant attenuating effect. Again, the overall effectiveness of gas protection mixtures is most easily seen in the normalized graphs.

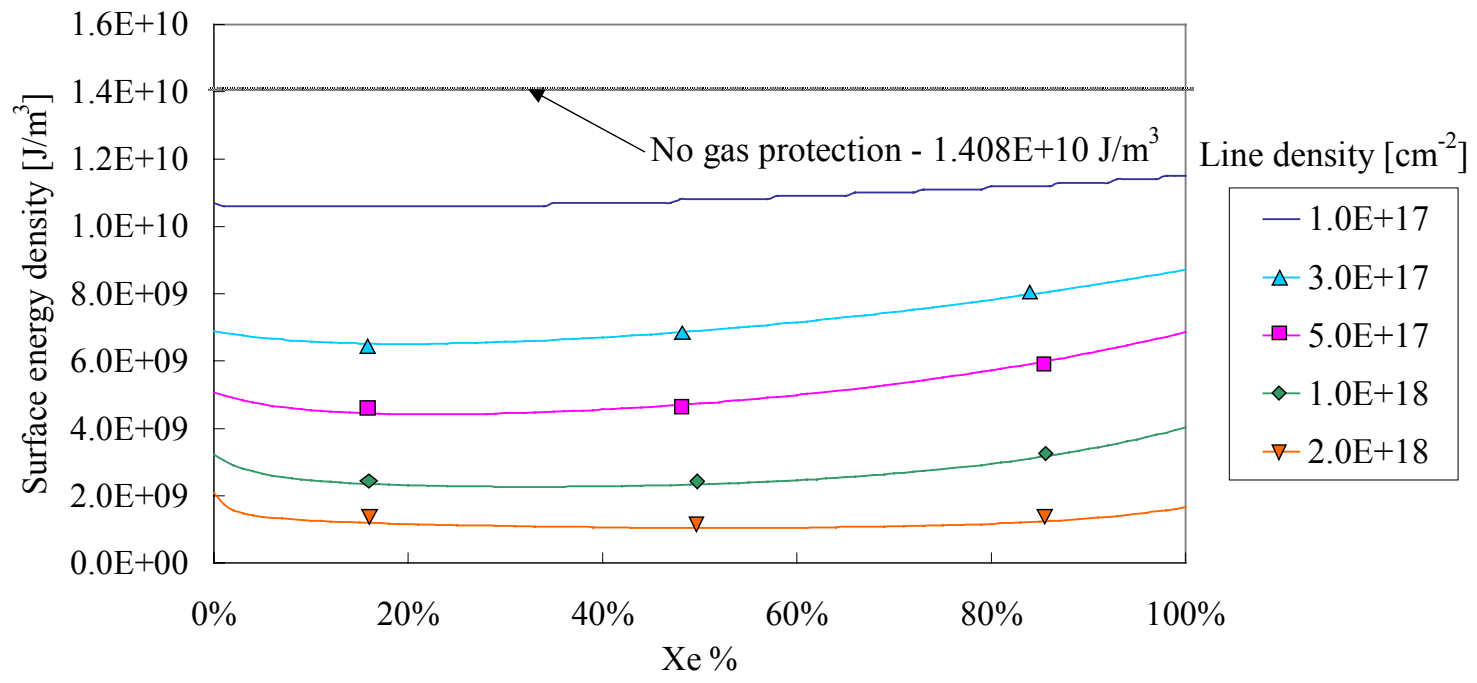

Figure 16: Surface energy density for aluminum at $30 \mathrm{~m}$ vs. attenuating gas composition $(\mathrm{Xe}, \mathrm{Kr})$

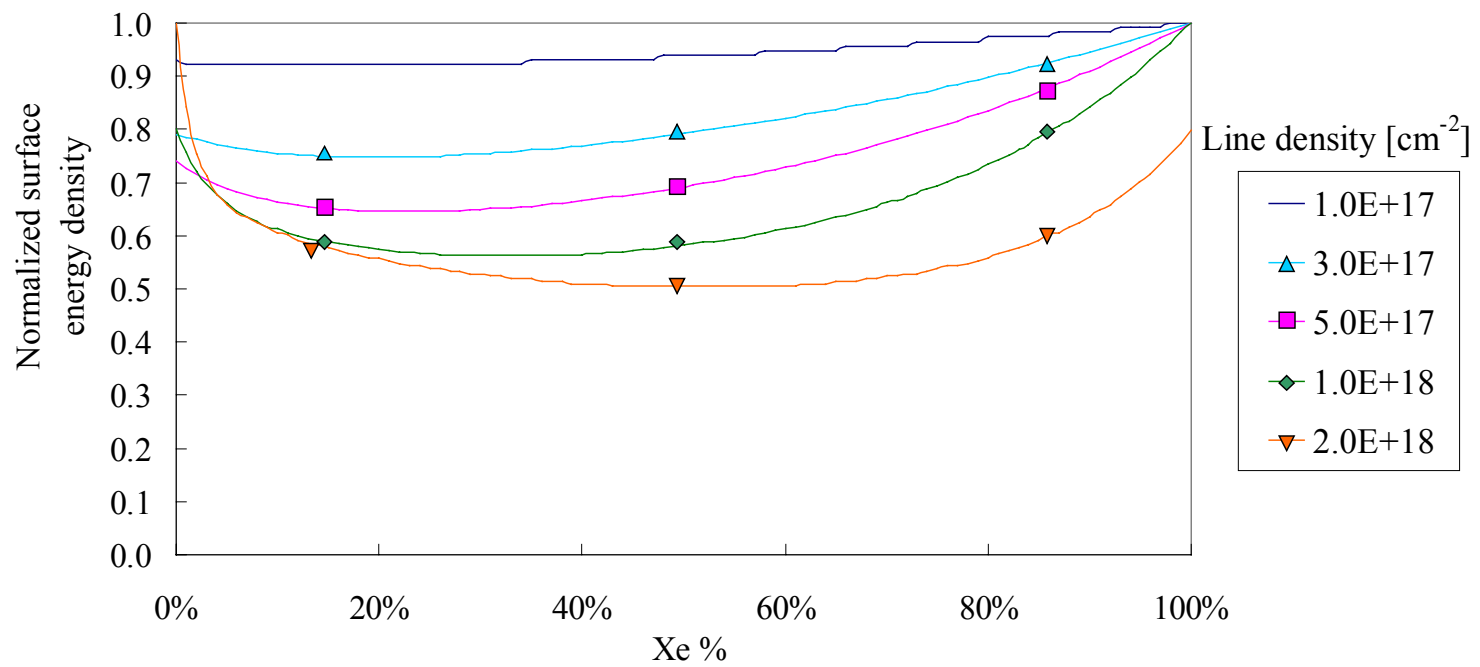

Figure 17: Normalized surface energy density for aluminum at $30 \mathrm{~m}$ vs. attenuating gas composition $(\mathrm{Xe}, \mathrm{Kr})$ 
The response of silica is very similar to those of aluminum. This is to be expected since the mean free paths for photons are similar for the two materials.

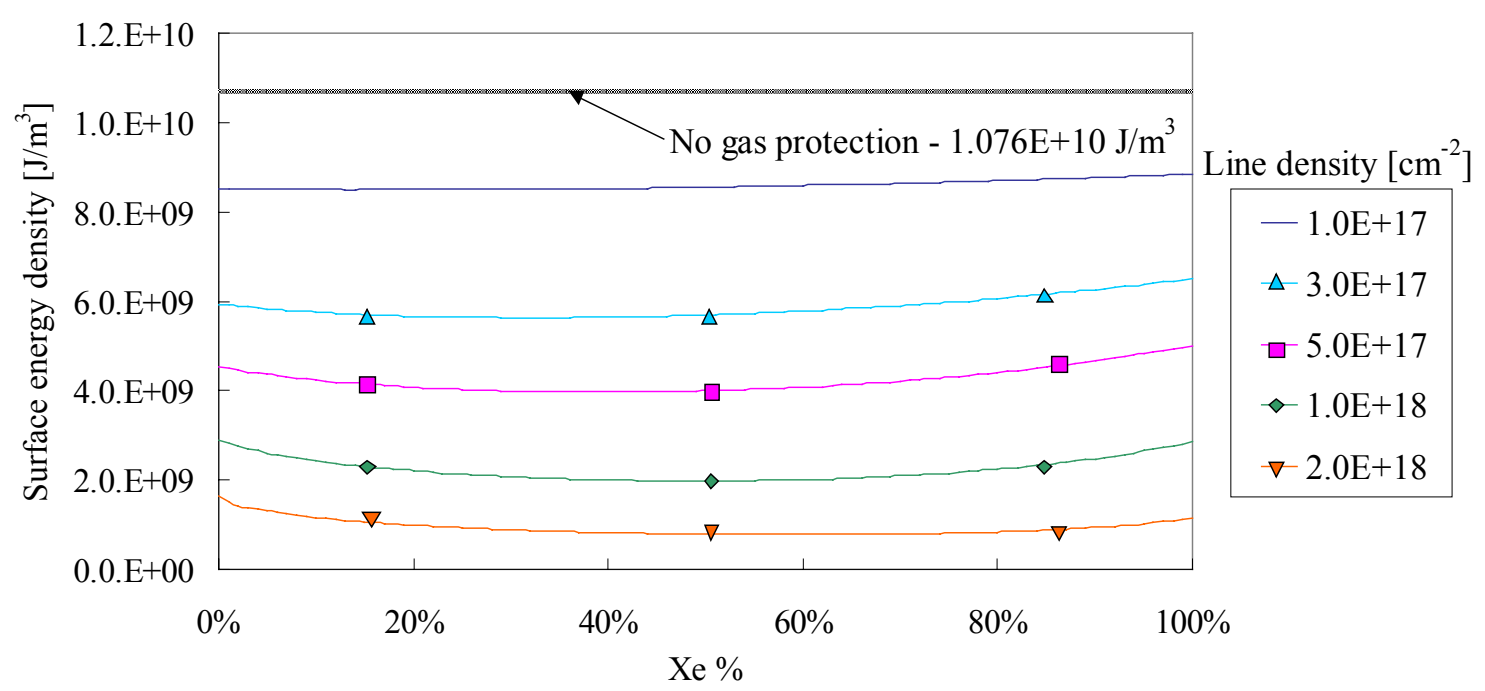

Figure 18: Surface energy density for silica at $30 \mathrm{~m}$ vs. attenuating gas composition ( $\mathrm{Xe}, \mathrm{Kr})$

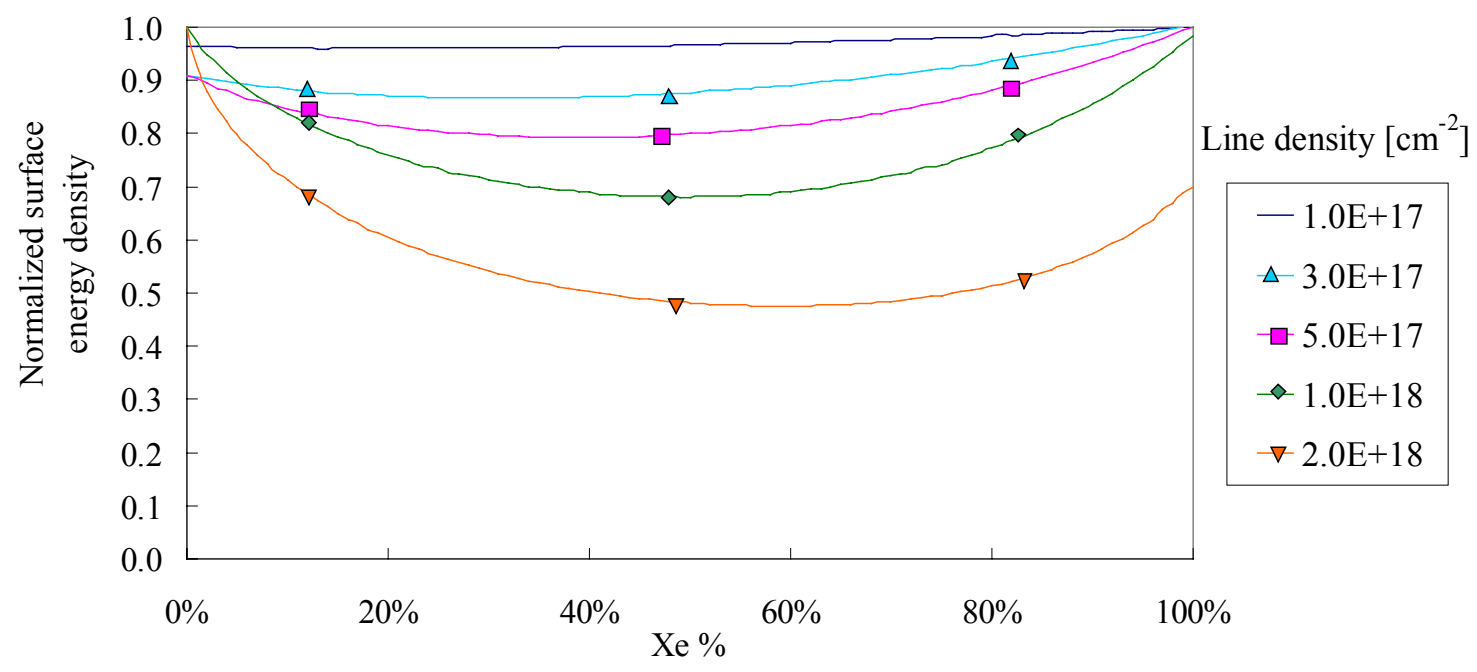

Figure 19: Normalized surface energy density for silica at $30 \mathrm{~m}$ vs. attenuating gas composition $(\mathrm{Xe}, \mathrm{Kr})$ 


\section{$\underline{\text { Protected Thin Films }}$}

Protected thin films have an attenuating gas layer to shield the material from the full brunt of the x-ray energy emitted by the target. This situation was considered because the heat transfer code does not consider phase change. With the exception of lithium, all the materials when exposed to the HI indirect-drive target at typical optical distances $(\mathrm{R} \sim 30$ $\mathrm{m})$ experienced surface temperatures greater than their boiling or melting point, depending on the initial phase of the material. This limits the analysis to situations where the material under consideration must remain in its initial phase. To this end, attenuating gases were employed to lessen the x-ray energy "seen" by the film. This study does not account for reemission from the gas or any other higher order effects.

Only sodium has been analyzed for the protected situation. The relationship between surface energy density and surface temperature rise is shown below for a gas line density of $3 \mathrm{E}+18 \mathrm{~cm}^{-2}$. This figure shows that temperature rise is strongly dependent on surface energy density. Also, temperature is only weakly dependent on gas mixture.

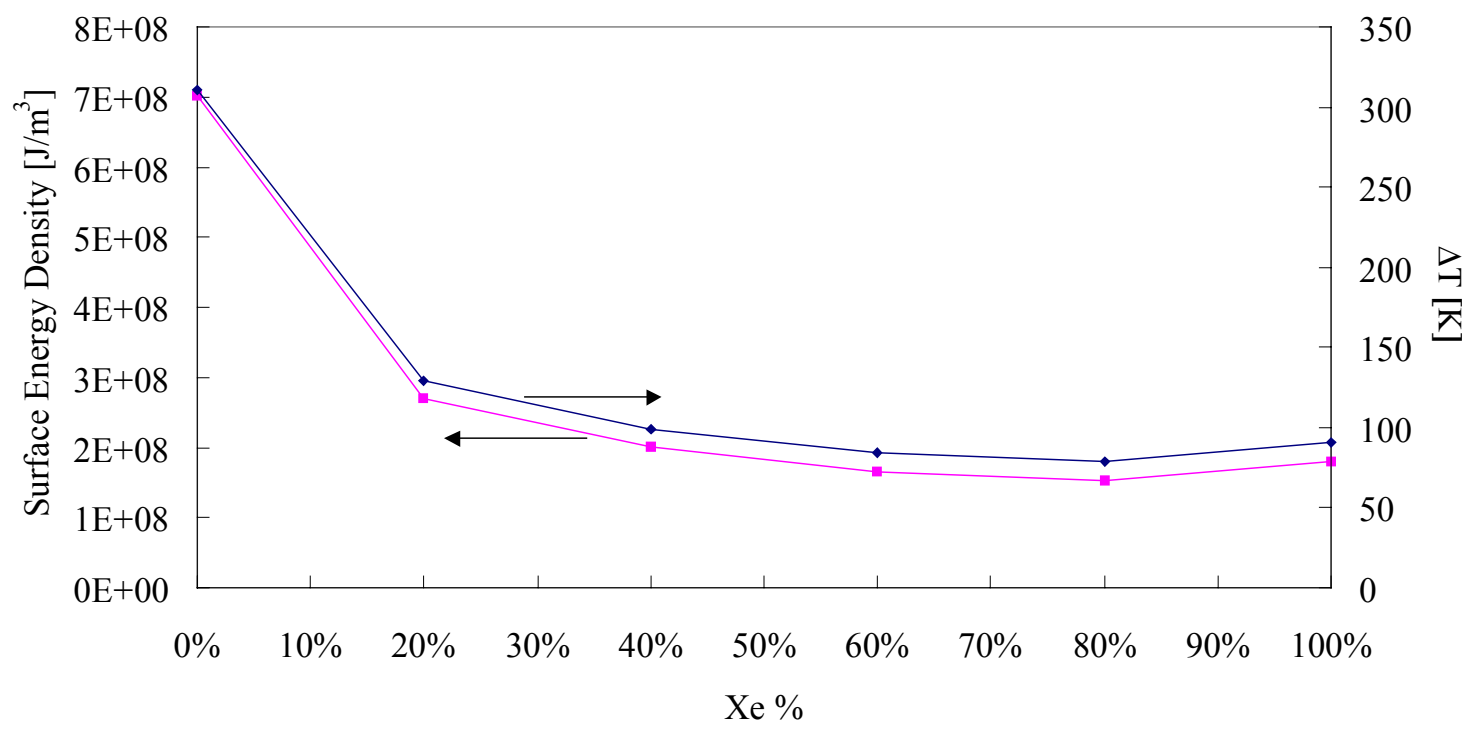

Figure 20: Surface temperature rise and energy density vs. Xe \% at a line density of $3 . \mathrm{E}+18 \mathrm{~cm}^{-2}$ for sodium at $\mathrm{R}=30 \mathrm{~m}$ and $\alpha=5^{\circ}$ 
The surface temperature rise for unprotected sodium GILMM's is plotted versus volumetric heat generation in Figure 21. Linear fits are also given.

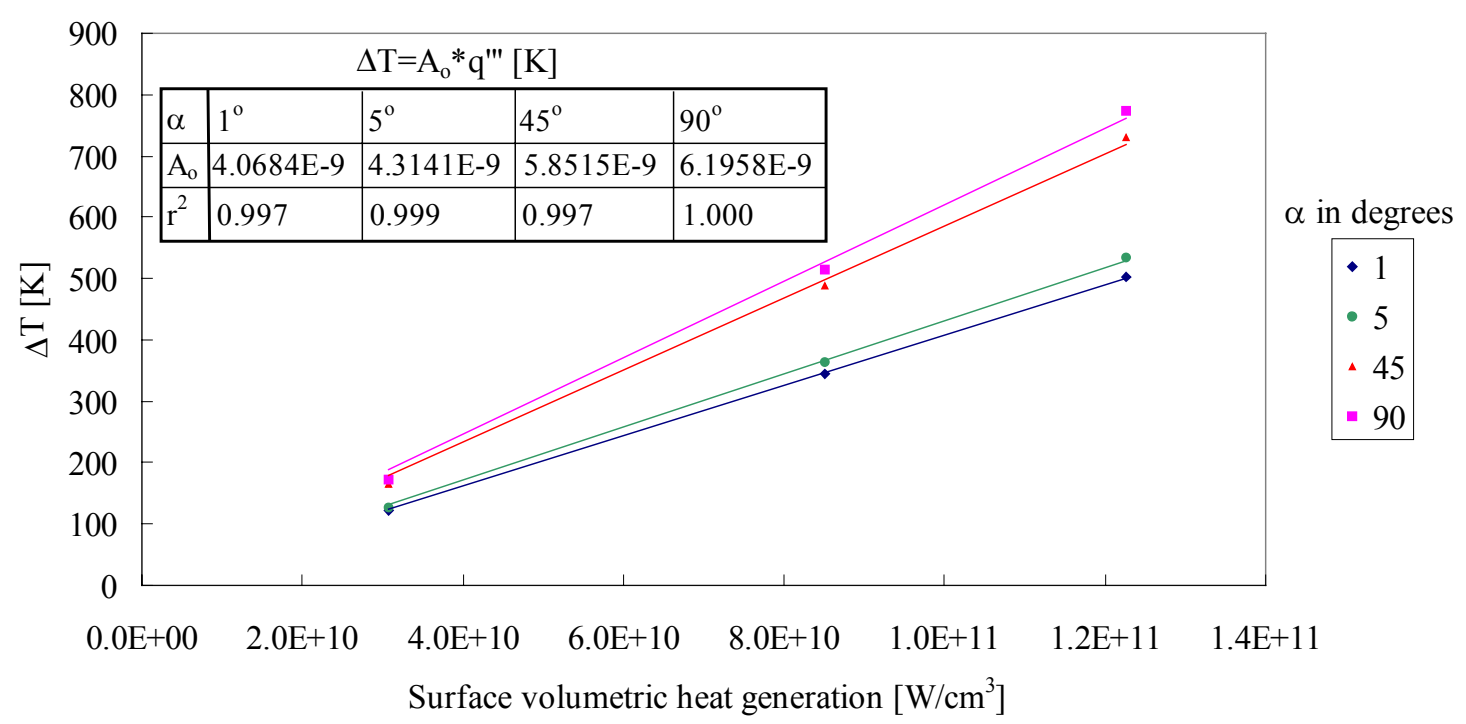

Figure 21: Surface temperature rise as a function of surface energy density for sodium films

This result can be used to relate surface temperature rise to the previous data given in Figure 12. The case of a sodium GILMM at an orientation angle of $5^{\circ}$ and a line density of $3 \cdot 10^{8} \mathrm{~cm}^{-2}$ (same as Figure 20 with $\mathrm{Xe} \%=80 \%$ ) is presented below.

$\left.\Phi\right|_{\mathrm{x}=0}=1.526 \mathrm{E}+8\left[\mathrm{~J} / \mathrm{m}^{3}\right]$ (surface energy density)

$\left.\mathrm{q}^{\prime \prime \prime}\right|_{\mathrm{x}=0}=\frac{\left.\Phi\right|_{\mathrm{x}=0}}{\tau} \cdot\left(\frac{1 \mathrm{~m}}{100 \mathrm{~cm}}\right)^{3}=1.526 \mathrm{E}+10\left[\mathrm{~W} / \mathrm{cm}^{3}\right] \quad$ (volumetric heat generation)

$\Delta \mathrm{T}=\left.\mathrm{A}_{\mathrm{o}} \cdot \mathrm{q}^{\prime \prime \prime}\right|_{\mathrm{x}=0}=\left(4.3141 \mathrm{E}-9\left[\mathrm{~K} \cdot \mathrm{cm}^{3} / \mathrm{W}\right]\right) \cdot\left(1.526 \mathrm{E}+10\left[\mathrm{~W} / \mathrm{cm}^{3}\right]\right)=\underline{\underline{65.8[\mathrm{~K}}}$

The actual calculated surface temperature rise is $79[\mathrm{~K}]$. The estimate is off by $18 \%$. The estimate improves for higher volumetric heat generation rates. The estimated temperature rise corresponding to a surface energy of $7 \mathrm{E}+8\left[\mathrm{~J} / \mathrm{m}^{3}\right]$ is $302[\mathrm{~K}]$. The actual calculated result is $310[\mathrm{~K}]$, or $3 \%$ higher than the estimate.

\section{Conclusions}

This work is the summary of numerical results of the two previously mentioned codes. These codes were extensively coupled for two different cases in this report. Sodium GILMM's exposed to the heavy ion indirect target and flibe first walls exposed to the direct drive target are these cases. Additional analyses using these models and the information presented here should be completed to more fully assess the implications for the operation of GILMM's and wetted first walls. 
The energy density code was used to obtain surface energy density results for GILMM and optical material candidates. These results are summarized in Figures 12-19. Using these results, a thermal analysis could be carried out for these materials.

A more general result is given by the surface energy flux from the indirect target. This is the surface flux attenuated by a gas mixture of xenon and krypton. This result could be used in the analytical solution to obtain a first approximation for the surface temperature of a GILMM with gas protection.

A method of estimating the surface temperature rise of a sodium GILMM exposed to the heavy ion indirect target is also given. This method is good for estimating the GILMM surface temperature at any distance and any gas protection.

\section{Acknowledgments}

This report would not have been possible without the invaluable efforts of the entire Fusion Energy Program. The work and encouragement of Judy Knecht, Jeff Latkowski, Wayne Meier, Susanna Reyes, and Robert Schmitt are deeply appreciated. As always, the guidance and support of my academic advisors, Dr. Minami Yoda and Dr. Abdel-Khalik, is also valued.

This research was performed under an appointment to the Fusion Energy Sciences Fellowship Program, administered by Oak Ridge Institute for Science and Education under a contract between the U.S. Department of Energy and the Oak Ridge Associated Universities.

This work was performed under the auspices of the U.S. Department of Energy by University of California Lawrence Livermore National Laboratory under contract No. W7405-Eng-48. 


\section{References}

1. S. G. Durbin, "SGD_Heat_1d_v1.mcd," MathCad code, LLNL, Unpublished, June 2001.

2. S. G. Durbin, "X-section_v2.mcd," MathCad code, LLNL, Unpublished, June 2001.

3. L. John Perkins, et al., "Output Threat Spectra from Direct and Indirect Drive IFE Targets," Presented ARIES Meeting, PPPL, September 19, 2000.

4. D. E. Cullen, "TART98: A Coupled Neutron Photon, 3-D, Combinatorial Geometry, Time Dependent, Monte Carlo Transport Code," LLNL, UCRL-ID-126455, Rev. 2 (1998).

5. Mofreh R. Zaghloul, University of California, San Diego, private communications, June 2001. 
University of California

Lawrence Livermore National Laboratory

Technical Information Department

Livermore, CA 94551

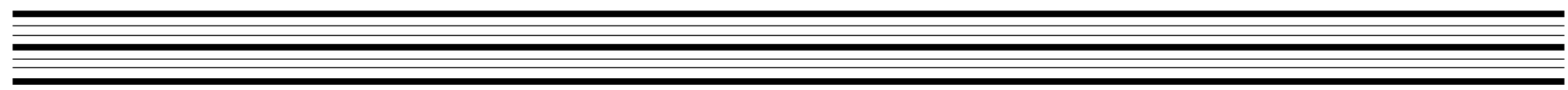

